\title{
Effect of dilute acid treatment on adhesion properties of Longmaxi black shale
}

\author{
Pan-Pan Zhang ${ }^{1,2} \cdot$ Shou-Ceng Tian $^{1,2} \cdot$ Mao Sheng $^{1,2} \cdot$ Tian-Yu Wang $^{1,2} \cdot$ Waleed Ali Khan ${ }^{1,2} \cdot$ Quan Xu $^{1} \cdot$ Li-Zhi Xiao $^{1,2}$
}

Received: 12 April 2019 / Published online: 5 October 2019

(c) The Author(s) 2019

\begin{abstract}
Properties of shale in an acid environment are important when acid or $\mathrm{CO}_{2}$ is injected into geologic formations as a working fluid for enhanced oil and gas recovery, hydraulic fracturing and reduced fracture initiation pressure. It has previously been shown that acid fluids can enhance the formation conductivity and decrease the hardness of shale. However, less is known about the effect of dilute acid on the adhesion properties of shale. In the study, shale samples are characterized in detail with advanced analysis. Adhesion properties of shale via dilute acid treatment were revealed by atomic force microscopy (AFM) for the first time. Results indicate that acid treatment can greatly enhance adhesion forces of the shale surface. After acid treatment, the average adhesion forces show a platform-like growth with an increase in loading force. Through analysis of results from AFM, scanning electron microscopy, and X-ray diffraction, we affirm that the enhanced adhesion forces are mainly from increased specific surface area and reduced elastic modulus. The results presented in this work help understand the adhesion properties of shale oil/gas present in an acidic environment, which have great significance in unconventional resources development.
\end{abstract}

Keywords Shale $\cdot$ Acid $\cdot$ Carbonates $\cdot$ Atomic force microscope $\cdot$ Adhesion force

\section{Introduction}

As an important alternative for conventional energy sources, shale gas development has been a great success with the wide application of horizontal drilling and multistage hydraulic fracturing (Collell et al. 2015; Tang et al. 2018). To get high conductivity fracture network and reduce the fracture initiation pressure underground, acidizing technology (Qi et al. 2012) and supercritical $\mathrm{CO}_{2}$ fracturing (Huang and Hu 2018; Ishida et al. 2012; Jiang et al. 2016; Ribeiro et al. 2017) were introduced in the development of shale reservoirs, which would create a weakly acidic environment in shale formations. Because of the general belief

Edited by Yan-Hua Sun

Shou-Ceng Tian

tscsydx@163.com

1 State Key Laboratory of Petroleum Resources and Prospecting, China University of Petroleum (Beijing), Beijing 102249, China

2 Harvard SEAS-CUPB Joint Laboratory on Petroleum Science, 29 Oxford Street, Cambridge, MA 02138, USA that the clay, silt, and organic matter (kerogen) comprising the major components of shale formations exhibit insignificant bulk solubility in acid, shale is thought to be relatively nonreactive to low pH or acidic fluids (Grieser et al. 2007). However, shale has highly diverse mineralogies and greatly varies with the region. For Longmaxi shale selected for the experiment, acid-soluble minerals account for nearly $10 \%$ and distribute in the rock matrix heterogeneously. For some regions, carbonates (calcite and dolomite) can account for up to $40 \%$ of shale (Dai et al. 2014; Yang et al. 2016). Calcite reacts with $\mathrm{HCl}$ to produce calcium chloride, water, and carbon dioxide, while dolomite reacts with $\mathrm{HCl}$ to produce calcium chloride, magnesium chloride, water, and carbon dioxide. Therefore, further research on the acid/shale reaction becomes necessary.

Grieser et al. (2007) mentioned that shale has many acidsoluble minerals that may be dissolved in low $\mathrm{pH}$ fluids resulting in the release of adsorbed gas. Wu and Sharma (2017) studied the effect of acid on shale microstructure and pore structure by directly comparing the SEM images. Morsy et al. (2013) quantified the impact of different concentrations of $\mathrm{HCl}$ solutions on physical properties and recoverability of shale formation. Al-Harahsheh et al. (2009) 
used a series of inorganic and organic acids to quantify the demineralization effect of shale on oil and gas yield. Guo et al. (2017) comprehensively evaluated acid fracturing treatments in shale formation and analyzed the permeability of acid-etched fracture in shale under the influence of various factors. Han et al. (2018) researched the mechanical behavior of Longmaxi shale by the micro-indentation test. Besides, the injection of $\mathrm{CO}_{2}$ into geological sites is believed to be an effective approach for $\mathrm{CO}_{2}$ sequestration, which creates an acidic environment in shale formation (Kalra et al. 2018; Kampman et al. 2014; Wan and Liu 2018; Yang et al. 2015; Yu et al. 2012).

Previous studies observed a positive correlation between shale oil/gas yield and acid treatment, but great deviations from this trend were also noticed. They found that acid treatment creates macroscopic cracks with high conductivity, but it also leads to a reduction in fracture conductivity caused by proppant embedment due to the reduced hardness of the shale fracture surface. Their study focused on the conductivity of macro-fractures caused by acid treatment aiming to optimize the design of acid fracturing in shale play. However, there are a large number of nanoscale pores and fissures in shale, where the release of oil and gas is controlled by the interaction (adhesion force) between the wall and fluid. At nanoscale, the intermolecular forces responsible for adhesion force could be caused by chemical bonding, van der Waals forces, and electrostatic force. For shale gas, the adsorption status is mainly controlled by the van der Waals forces (Wang et al. 2016; Wu et al. 2015) and shale gas in absorbed phase can reach $85 \%$ of the total gas-in-place (Curtis 2002). AFM, with its high vertical resolution, can detect the tip/sample interaction force (adhesion force) (Tian et al. 2018), and it is crucial for understanding the flow behavior of oil and gas at nanoscale. Up to now, little research has been conducted on adhesion properties of shale before and after acid treatment and there has not been a unified understanding of acid treatment in shale formations. Therefore, research on the adhesion properties of shale becomes meaningful and necessary, which can illustrate the adhesion capability of shale in an acidic environment.

In present work, shale from the Longmaxi group, a representative of marine sediments in China, was selected to study the effect of acidizing on adhesion forces by AFM. Enhanced adhesion forces of shale surface after dilute acid treatment were innovatively observed. Besides, topographic images were constructed in non-contact atomic force microscopy mode before and after acidizing. Then, morphology changes of shale surface were investigated by using SEM imaging. Evolution of shale's microstructure and elemental abundance before and after acid treatment was obtained with SEM imaging and energy dispersive spectrometer (EDS) scanning. Finally, in order to explain the intrinsic mechanism of the enhanced adhesion capability, we analyzed the mineral composition and the mechanical properties of the shale sample before and after acid treatment by XRD and nanoindentation, respectively.

\section{Methodology}

\subsection{Sample and preparation}

Shale samples were outcrops collected from the Silurian Longmaxi Formation, Sichuan Basin, China. Mineralogy information of shale was obtained by X-ray diffraction (shown in Table 1). Detailed information on the geology setting and shale geochemistry of this formation can be found in previous investigations ( $\mathrm{Jia}$ et al. 2012; Li et al. 2018; Liu et al. 2019; Zhou et al. 2014). To get a section suitable for SEM and AFM tests, we cut the sample mechanically into small flakes with a surface area approximately $10 \mathrm{~mm} \times 10 \mathrm{~mm}$. Then, the flakes were manually polished on the surface with sandpapers from coarse to fine (up to 3000 grit).

\subsection{Mineralogical analysis}

XRD can accomplish the identification of crystalline phases in rocks quickly and accurately (Chen et al. 2014; Srodon et al. 2001; Tong et al. 2011). To quantify the effects of acid treatment on mineralogy, the sample was ground to powders to suit XRD sample preparation requirements. The powders were divided into two parts, one of which was subjected to XRD test directly. The other part was used for the same XRD test after acid treatment. To get post-acidizing powders, a sufficient amount $(50 \mathrm{~mL})$ of $3 \% \mathrm{HCl}$ was prepared to react with $2 \mathrm{~g}$ of powder sample in a beaker and stirred with a rod for 30 min every $12 \mathrm{~h}$ under ambient temperature.

Table 1 Mineral components of samples before and after acid treatment

\begin{tabular}{llllllll}
\hline Minerals & \multicolumn{2}{l}{ Mineral content, wt } & & & \multirow{2}{*}{ Total, \% } \\
\cline { 2 - 7 } & Quartz & Clay & Carbonates & Feldspar & Pyrite & Siderite & Gypsum \\
\hline Before acid treatment & 45.7 & 36.5 & 7.9 & 5.9 & 3.2 & 0.5 & 0.3 \\
After acid treatment & 49.8 & 35.7 & 0 & 10.7 & 3.8 & 0 & 0 \\
\hline
\end{tabular}


After $48 \mathrm{~h}$, the mixture was filtered through a $0.45 \mu \mathrm{m}$ filter paper and then washed with an excess amount of distilled water to remove acid residuals. The solid residual was then dried at $90{ }^{\circ} \mathrm{C}$ for $24 \mathrm{~h}$ in an oven to remove moisture. In the experiment, Rigaku MiniFlex II Desktop X-ray Diffractometer with a $\mathrm{Cu}$ anode producing $\mathrm{X}$-rays was used. The diffractometer was operating at $40 \mathrm{kV}$ and $20 \mathrm{~mA}$, scanning values $2 \theta$ ranged from $2.5^{\circ}$ to $45^{\circ}$ with a step size of $0.02^{\circ}$ and a scan speed of $1 \% \mathrm{~min}$.

\subsection{Experimental procedure}

Through relative coordinates and marks, the same location on the surface was observed pre- and post-acidizing with a multi-functional field-emission scanning electron microscope (FE-SEM, SU8010). All images were obtained with an acceleration voltage of $20 \mathrm{kV}$ and a current of $15.6 \mu \mathrm{A}$. Elemental scanning was performed through EDS detectors equipped in SEM. After operations on the pre-acidizing sample, the sample was taken out from the sample chamber for acid treatment. Two drops of $1 \mathrm{wt} \% \mathrm{HCl}$ were applied to the polished surface for $1 \mathrm{~min}$ and then rinsed off with distilled water at ambient temperature. To remove residual water on the surface, the sample was dried in air under a lamp for $30 \mathrm{~min}$. SEM imaging and EDS scanning were performed at the same position on the post-acidizing sample.

Adhesion forces were quantified using AFM (Dimension Icon AFM, Bruker Co., Inc.), and schematic of the AFM is shown in Fig. 1. The sample preparation procedure in the AFM test was similar to that in the SEM part. A silica microsphere with a diameter of $10 \pm 0.25 \mu \mathrm{m}$ was carefully glued at the end of a tipless probe, and its SEM image is shown in the inset of Fig. 1. The AFM cantilever used in the experiment was $225 \mu \mathrm{m}$ in length, $50 \mu \mathrm{m}$ in width and $4 \mu \mathrm{m}$ in thickness, with an average spring constant of $20 \mathrm{~N} / \mathrm{m}$ and an average frequency of $100 \mathrm{kHz}$. Reaction velocity was

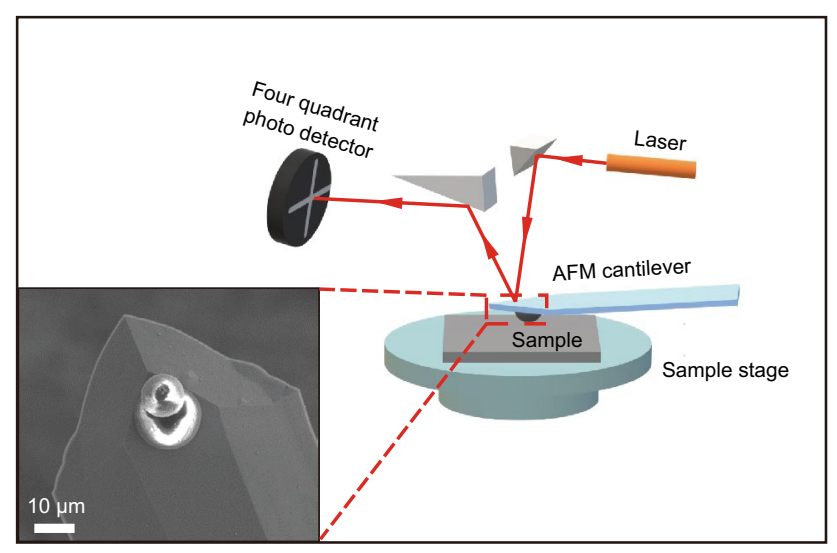

Fig. 1 Schematic of the AFM scanning system with an inset of SEM image of glued silica microsphere set at $1.62 \mu \mathrm{m} / \mathrm{s}$, and the test was conducted under room temperature with humidity controlled at $20 \%$. Six positions on the sample surface were randomly selected before and after acid treatment. Different loading forces were applied to these positions from 500 to $3000 \mathrm{nN}$ to get adhesion forces. In the same way, a ScanAsyst-Air probe with a spring constant of $0.4 \mathrm{~N} / \mathrm{m}$ was used to construct topographic images of shale surface by measuring the tip-to-sample distance at each $(x, y)$ data point. In this process, we selected visually flat areas for topographical scanning before and after acid treatment. Detailed testing principles and knowledge about AFM can be found in previous studies (Binnig et al. 1986; Butt et al. 2005; Javadpour et al. 2012; Xu et al. 2013, 2014). In addition, the measurement of mechanical properties of the shale surface was taken by a Nano Indenter G200 at room temperature and pressure, which can measure the elastic modulus and hardness in compliance with ISO 14577. The surface-approaching velocity was set at $30 \mathrm{~nm} / \mathrm{s}$ with a final indentation depth of $5000 \mathrm{~nm}$.

\section{Results}

\subsection{Effect of dilute acid treatment on adhesion forces}

Interactive forces between surfaces are the signature of surface materials (Javadpour et al. 2012). Previous studies had been illustrated using distinct force interactions to study and characterize shale samples (Tian et al. 2018). In this experiment, we randomly selected six positions on the sample surface and concentrated on adhesion force changes before and after dilute acid treatment. Figure $2 \mathrm{a}, \mathrm{b}$ shows the adhesion forces of the six points with loading force ranging from 500 to $3000 \mathrm{nN}$ before and after acid treatment. With an increase in loading force, the adhesion force of pre-acidizing sample remains relatively stable for every position, revealing that the test occurred in the elastic range. After acid treatment, the adhesion forces exhibit an obvious upward trend with an increase in loading force. Due to the complex morphology and strong heterogeneity of the shale surface, the surface deforms nonlinearly or even gets crushed with an increase in loading force. Therefore, the trend of curves shows a platform-like rise rather than a monotonous increase. The relationship between average adhesion forces at the six points and loading force is clearly demonstrated in Fig. $2 \mathrm{~d}$. For loading forces lower than $800 \mathrm{nN}$, the pre-acidizing and post-acidizing samples show a slight difference in adhesion forces. With loading force increasing, the average pre-acidizing adhesion forces fluctuate between 25 and $35 \mathrm{nN}$, whereas for the curve of the post-acidizing sample, adhesion forces raise by 3 times from less than $30 \mathrm{nN}$ to more than $90 \mathrm{nN}$. For higher loading force, the post-acidizing adhesion forces 

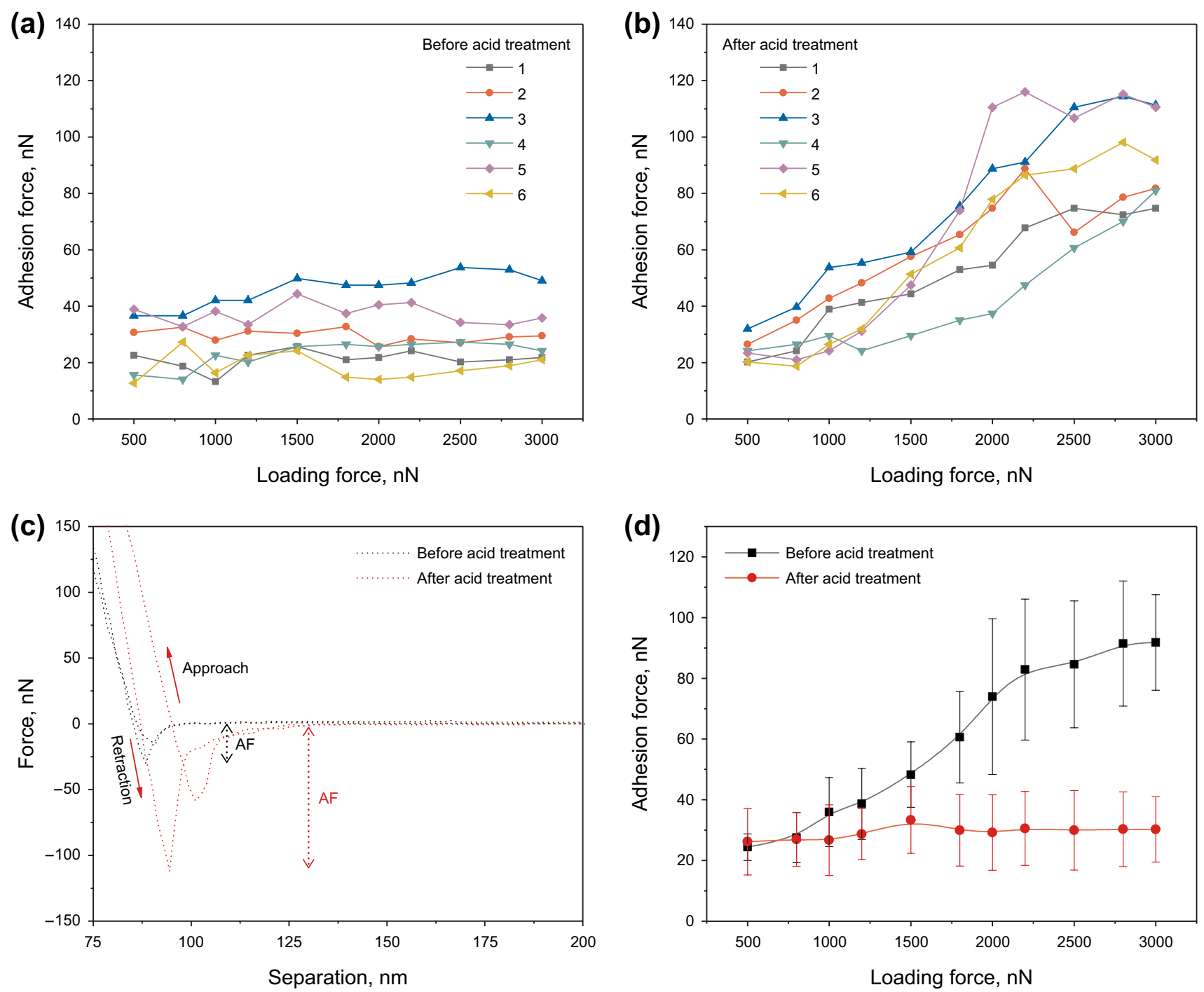

Fig. 2 Adhesion forces of six points with different loading forces $\mathbf{a}$ before and $\mathbf{b}$ after acid treatment. $\mathbf{c}$ Typical pre- and post-acidizing adhesion curves at loading force $2200 \mathrm{nN}$. d Statistical average adhesion force with different loading forces before and after acid treatment

are significantly greater than that of pre-acidizing. Typical adhesion curves (Fig. 2c) give a clear demonstration that the adhesive force (AF) increased due to acid treatment at a high loading force. Xu et al. (2013) had shown that the adhesion force increases after the loading force exceeding the critical value. Therefore, dilute acid treatment can effectively reduce the critical value of the loading force in this study.

\subsection{Topography and surface roughness study}

Surface topography was mapped before and after acid treatment in non-contact atomic force microscopy mode. Because the scanning range of AFM in the vertical direction is limited and the sample surface is relatively uneven after acid treatment, relatively flat areas were selected for topography mapping before and after acid treatment. Considering that the Longmaxi shale is relatively porous and micron to nanometer pores exist in the matrix of minerals (Dai et al. 2014), the roughness is sensitive to the size of tested areas.

Figure $3 \mathrm{a}, \mathrm{b}$ are plane and stereo topographic images of the shale surface before acid treatment, respectively, and the roughness $(R a)$ of the selected area $(10 \mu \mathrm{m} \times 10 \mu \mathrm{m})$ is $35 \mathrm{~nm}$. Similarly, Fig. 3c, d shows the topographic images of the same size after acid treatment with a roughness of $48.1 \mathrm{~nm}$. It is worth noting that stereo images have been stretched in the vertical direction for better visualizing. In the real size, the surface is much flatter due to the small change in the vertical direction. When narrowing the analyzed area to $1 \mu \mathrm{m} \times 1 \mu \mathrm{m}$, the areal roughness before and after acid treatment decreased significantly to $8.43 \mathrm{~nm}$ and $13.6 \mathrm{~nm}$, respectively, (Fig. 4). On the mesoscopic scale, changes in surface topography before and after acid treatment can be 


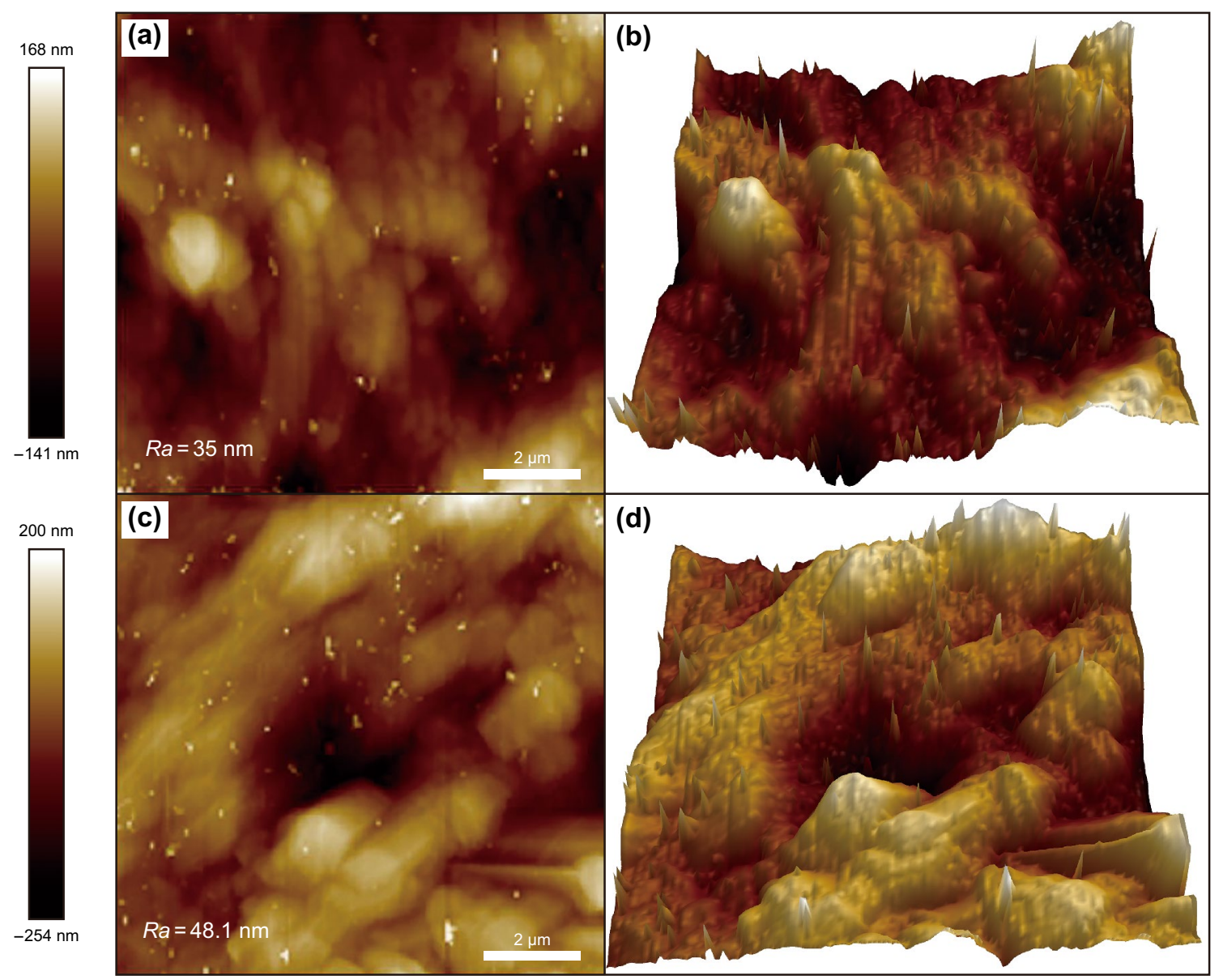

Fig. 3 a, b Plane and stereo topographic images of the shale surface before acid treatment. $\mathbf{c}, \mathbf{d}$ Plane and stereo topographic images of the shale surface after acid treatment (area: $10 \mu \mathrm{m} \times 10 \mu \mathrm{m})$

seen in Fig. 5a, b, where the polished surface is destroyed by acid treatment.

\subsection{Microstructure and elemental composition study}

With relative coordinates and markers recorded during imaging of the pre-acidizing sample, the same image fields were relocated successfully after acid treatment. In order to obtain original surface topography, the coating was not used during imaging and scanning to avoid potential interference. A direct visual comparison (Fig. 5a, b) and elemental abundance analysis (Fig. 5d, e) are made before and after acid treatment. In the selected filed, the total proportions of oxygen, silicon, carbon, and aluminum are more than $95 \%$ (Fig. 5d), suggesting its high content of quartz, organic matter, and clay minerals. Elements of calcium and magnesium only account for $2.34 \%$ by weight and mainly distribute in the white spots in Fig. 5a. The EDS scanning results before and after acid treatment are shown in Fig. 6. The elemental information from EDS analysis is basically consistent with that from mineral analysis by XRD, which ensures the rationality of the data.

The XRD analysis shows the mineral composition of the untreated sample and sample after acid digestion in Table 1. Clay and quartz are the main components of mineral matter in the shale sample. Both quartz and clay minerals contain oxygen, which explains the oxygen content of $49.2 \%$ from EDS analysis. Proportions of carbonates, feldspar, and pyrite contents are $7.9 \%, 5.9 \%$, and $3.2 \%$, respectively, which are relatively low but cannot be ignored. After reacting with $3 \%$ $\mathrm{HCl}$ for $48 \mathrm{~h}$, carbonates, siderite, and gypsum were digested and disappeared in the residual. Correspondingly, one of the changes that can be noticed in Fig. 6 is that the peak of calcium decreased after acid treatment. The relative content of other minerals raised slightly or remained stable under the function of carbonates dissolution.

Because the main minerals that react with acids are carbonates, the distribution of carbonates in the preacidizing sample directly affects the microstructure and pore structure after the dissolution of the carbonates. Due to the random distribution of carbonates, the dissolution 


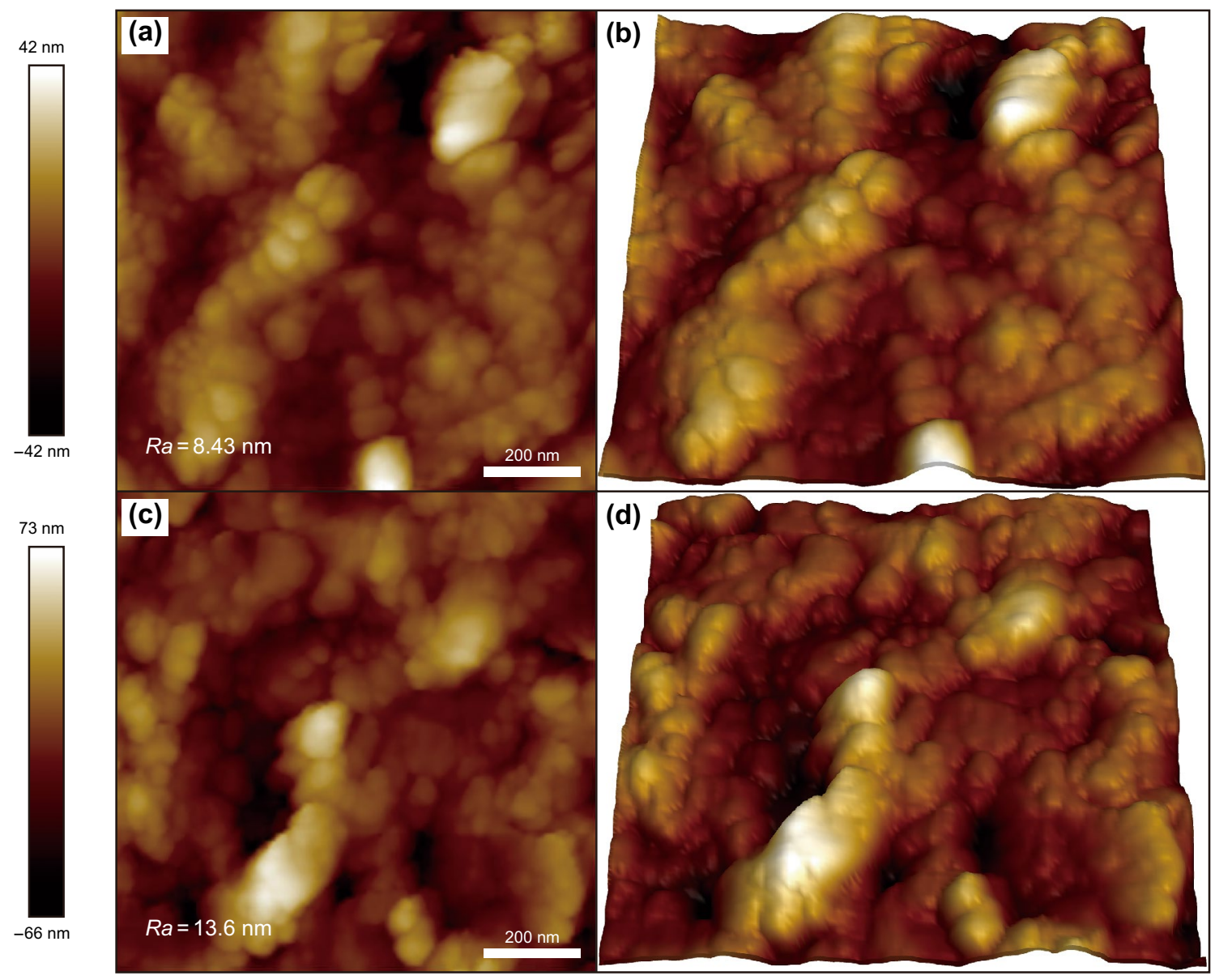

Fig. 4 a, b Plane and stereo topographic images of the shale surface before acid treatment. $\mathbf{c}, \mathbf{d}$ Plane and stereo topographic images of the shale surface after acid treatment (area: $1 \mu \mathrm{m} \times 1 \mu \mathrm{m})$

of carbonates caused by acidizing forms a great many of cavities and pits (Fig. 5c) on the sample surface, which can promote pore connectivity and facilitates the release of shale gas. Adhesion properties also change with alterations of surface topography and mineral composition.

Most carbon exists in an organic form with a small amount in calcium carbonate. The reaction of carbonates with hydrochloric acid releases carbon dioxide and causes a slight decrease in carbon content. About $80 \%$ decrease in calcium is observed due to the dissolution of the carbonate (Fig. 5e). The reaction rate for calcium carbonate is rapid and is transport limited, while the reaction with dolomite is slower and is reaction rate limited (Patton et al. 2003). In the experiment, only two drops of dilute acid $(1 \% \mathrm{HCl})$ were applied to the shale surface and reacted for $1 \mathrm{~min}$. Taking the widespread substitution of magnesium ions in clay minerals and instrument error into consideration, it is reasonable to observe a minor increase in magnesium. The content of silicon, aluminum, and other elements shows a slight ascent due to the dissolution of calcium carbonate.

\section{Discussion}

Our experiments show that dilute acid treatment exerts a strong influence on chemical compositions and surface morphology of shale, which in turn affects the adhesion properties of the shale. Since the primary concern of this research is to study the adhesion properties of shale in an acidic environment, rather than to examine the digestion efficiency of different types of acid, only diluted hydrochloric acid is used in this experiment.

For acid reacts with carbonates preferentially, and only two drops of diluted $\mathrm{HCl}$ were used in the adhesion force test, we focus on the mineralogical and topographical changes to clarify the effect of dilute acid treatment on adhesion properties of shale. After acid treatment, carbonate minerals are digested, and morphology of the sample surface changes accordingly. Masses of cavities and pits form due to the dissolution of non-uniformly distributed carbonates, and both AFM height images and SEM images can give an illustration of increased surface roughness. The in situ stress exerted on the shale varies greatly, which 

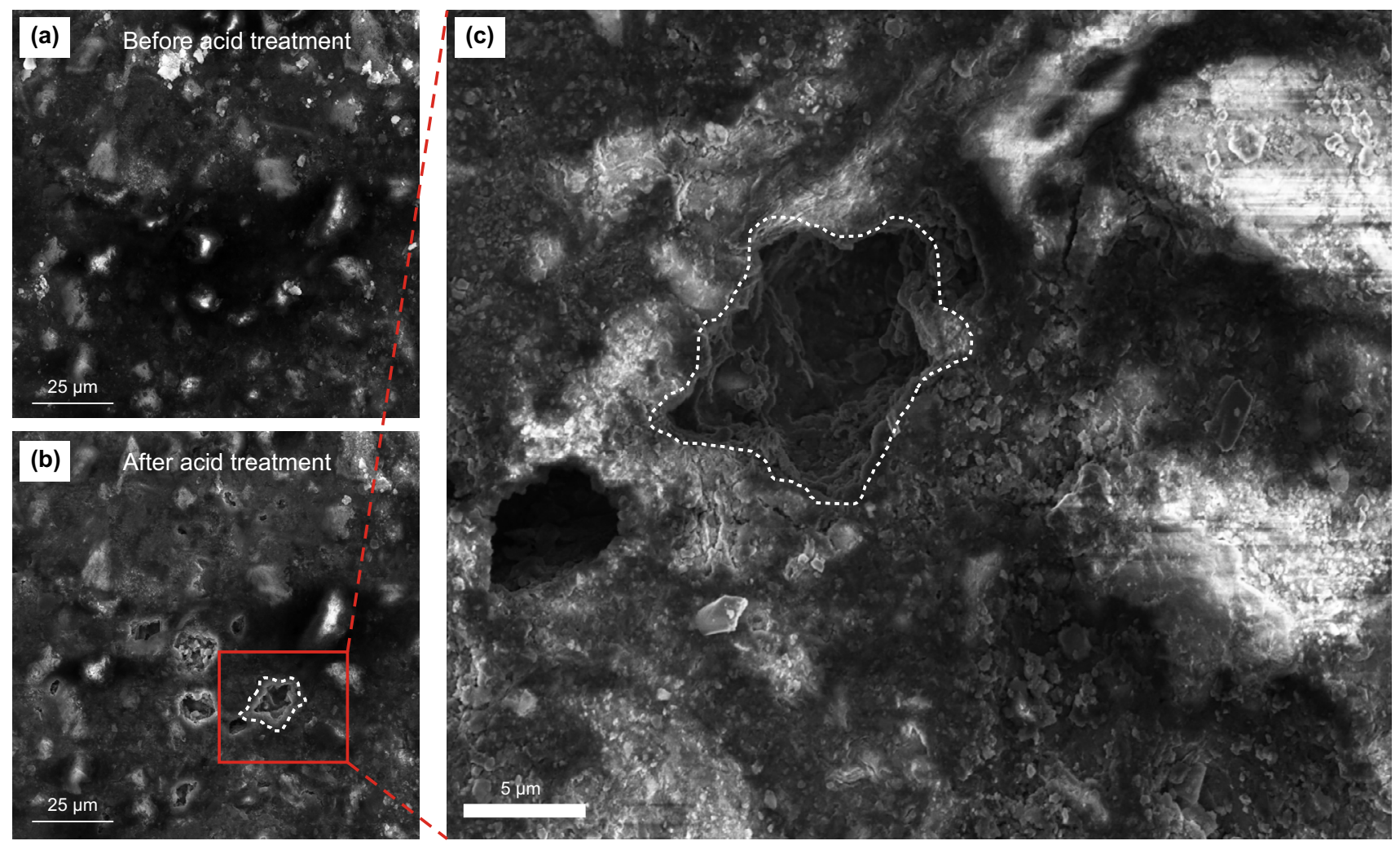

(d)

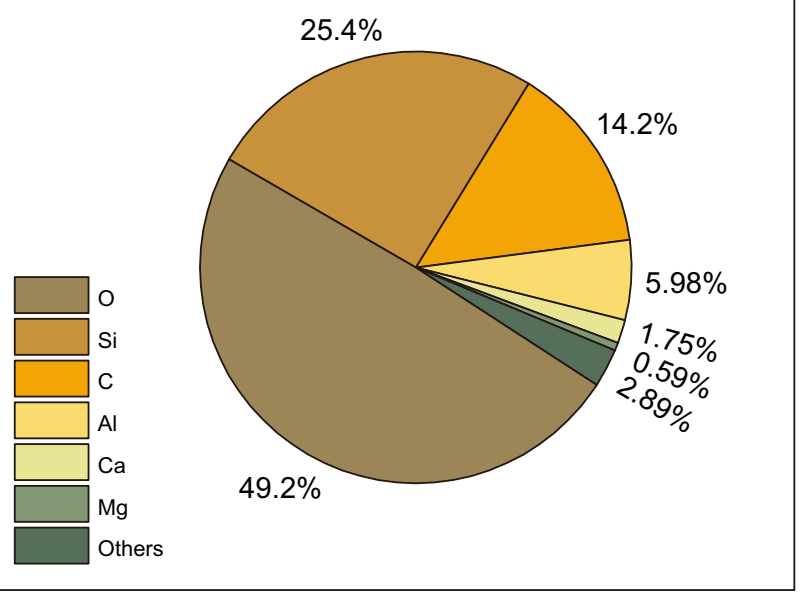

(e)

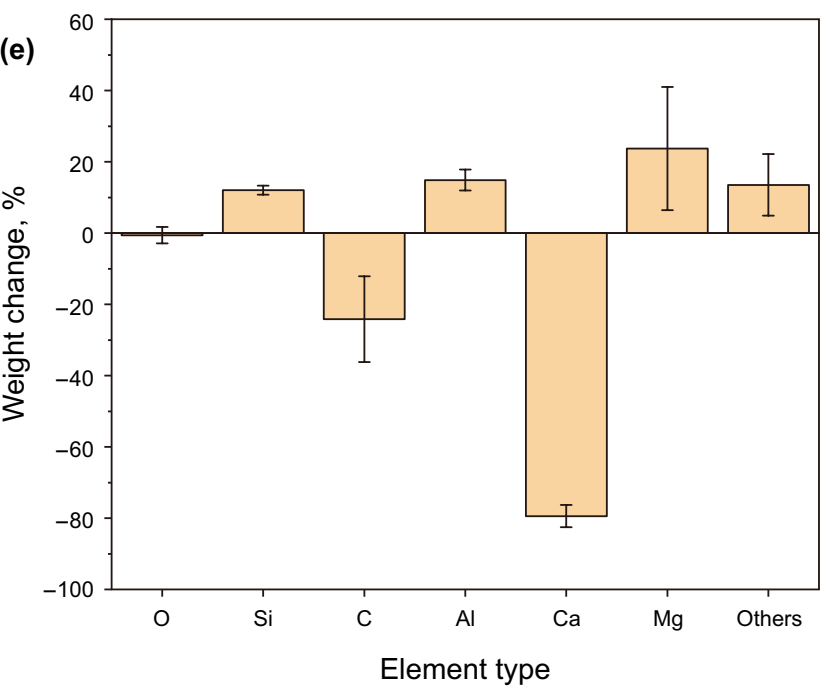

Fig. 5 SEM images of the selected area $\mathbf{a}$ before and $\mathbf{b}$ after acid treatment. $\mathbf{c}$ A zoom-in of box-region of $\mathbf{b}$. $\mathbf{d}$ Elemental composition by weight of region a before acid treatment. e Elemental abundance changes after acid treatment of region $\mathbf{b}$

may affect the adsorption and flow of oil and gas on the shale surface. Therefore, adhesion properties under different loading forces are studied. Enhanced adhesion forces of shale surface at high loading forces are observed after acid treatment in this study.

Previous experiments have shown that the hardness and elastic modulus of shale are reduced after the saturation of acidic fluids (Guo et al. 2017; Zhang et al. 2017). In this study, we obtained similar results by the nanoindentation test, which is a well-known method for the microscale to nanoscale mechanical characterization of materials (Lei et al. 2016). The decreased elastic modulus and hardness (as shown in Figs. 7, 8) might be responsible for the enhancement of the adhesion force. 

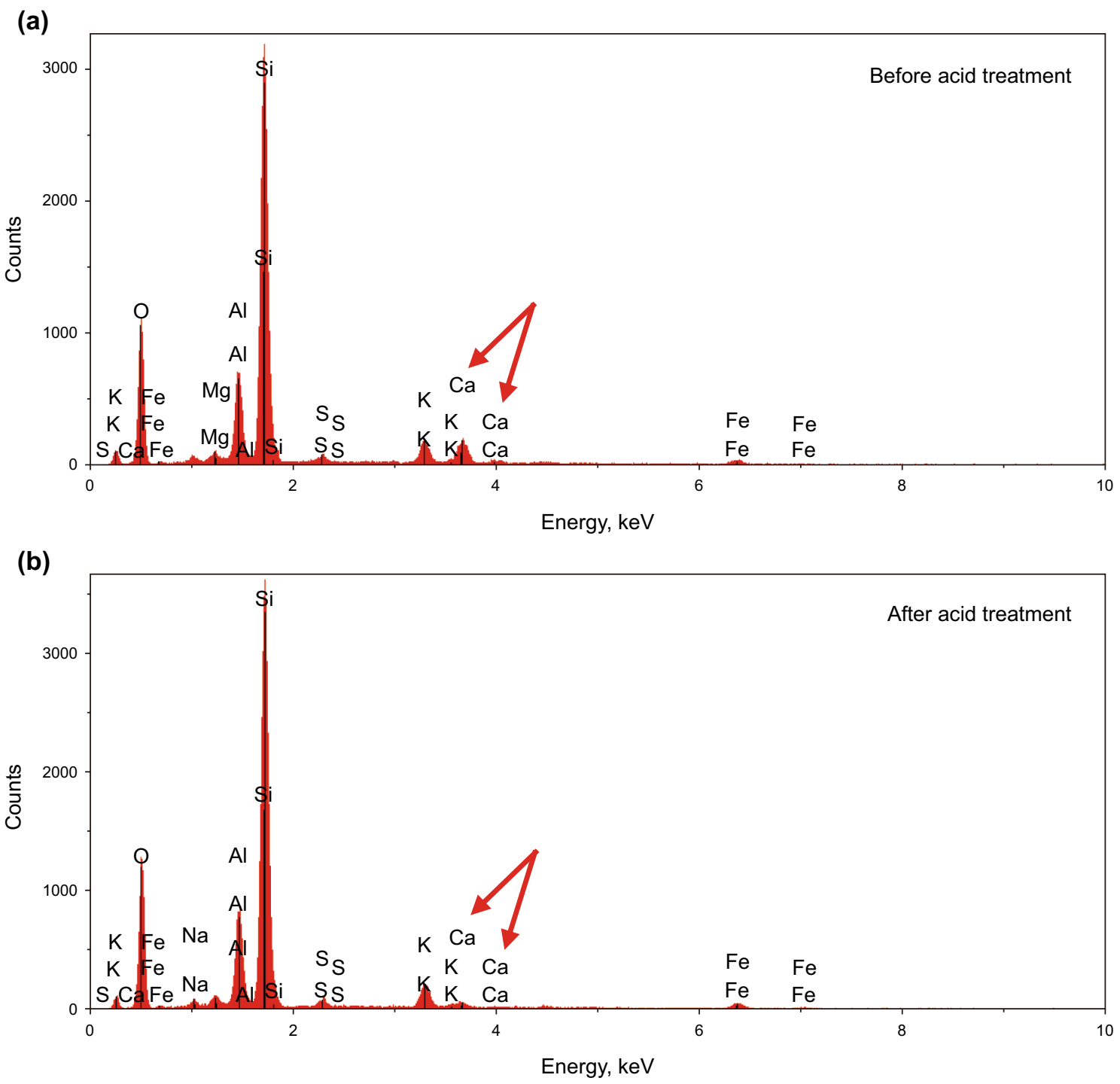

Fig. 6 EDS scanning of the selected area before and after acid treatment

At the atomic or molecular scale, adhesion force emerges from intermolecular forces such as chemical bonding, van der Waals forces, and electrostatic force (Israelachvili 2011). In this study, the van der Waals forces were expected to dominate among these intermolecular forces. For the probes used in this experiment are electrically neutral, electrostatic forces can be excluded from adhesion. Besides, the force curve drops off fast and becomes zero for few nanometers away, which contradicts the long-range nature of the electrostatic force (Butt et al. 2005; Inui and Iwasaki 2017). Considering the chemical nature of the substrate and the silica tip, the approaching/separation process is considered to be physical, and new chemical bonds are unlikely to form between them at room temperature. Moreover, the precise force separation curve of chemical bonding, such as ionic or covalent, is practically unmeasurable because of the instability of jumping (Kendall 1994).

In addition to these intermolecular forces, there are also certain mechanical effects, among which mechanical interlock is a well-known mechanism of adhesion (Ebnesajjad and Landrock 2014; Paddy et al. 1987). Adhesion from mechanical interlock increases with the roughness of substrates (Jennings 1972), possibly through the increase in energy dissipation and interfacial area (Yang et al. 2019). Because the surfaces of the tip and the substrate are not perfectly smooth (Butt et al. 2005) and integrity of the sample surface is destroyed by acid treatment, mechanical friction at the microscale can also be a part of the adhesion (Yang et al. 2019). Therefore, the adhesion force between the shale surface and the silica microsphere is considered to be dominated by the mutual function of van der Waals forces 


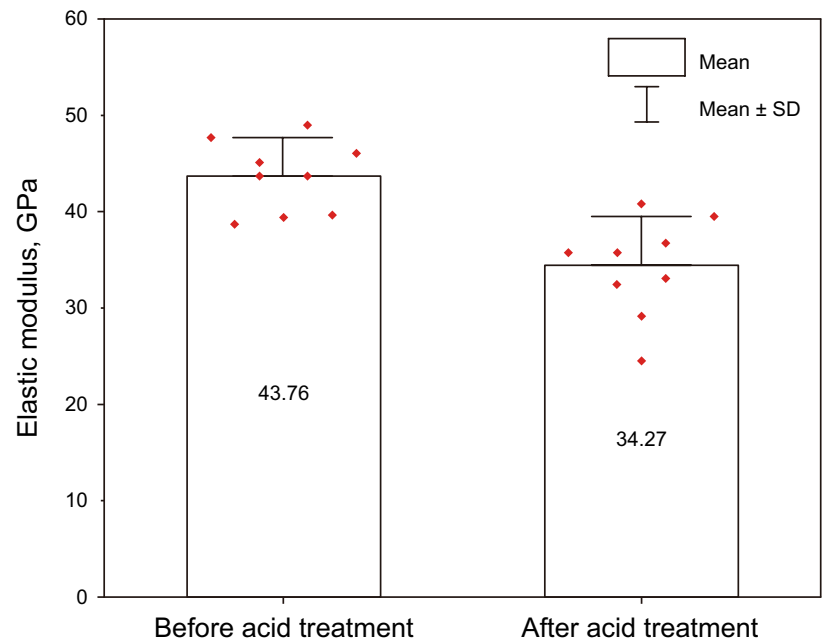

Fig. 7 Elastic modulus of the sample obtained by the nanoindentation test before and after acid treatment

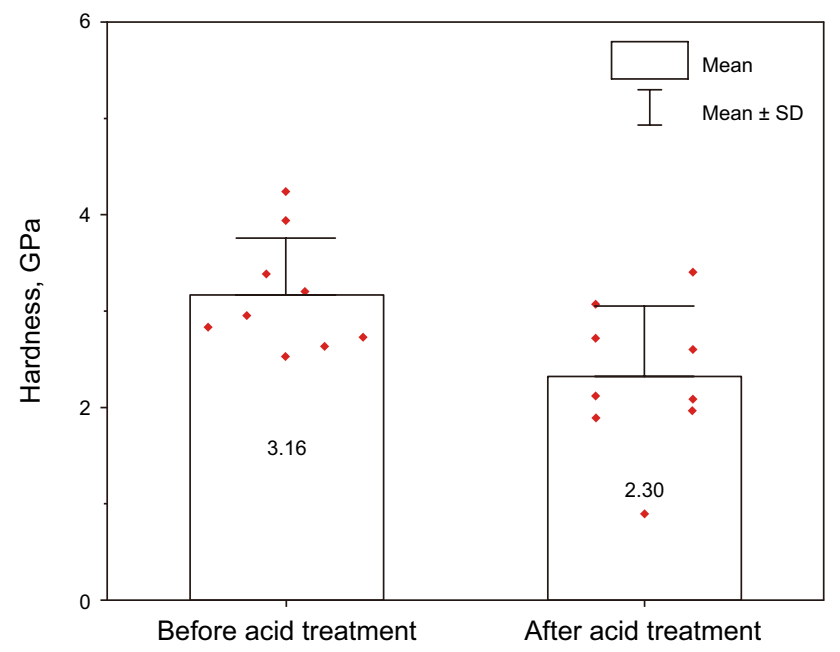

Fig. 8 Hardness of the sample obtained by the nanoindentation test before and after acid treatment

and energy dissipation considering the absence of chemical bonding and electrostatic force.

Taking the topographic changes and plastic deformation into consideration, Fig. 9 gives a dynamic model that explains well to the adhesion property changes before and after acid treatment. When the loading force increases from 500 to $3000 \mathrm{nN}$, the shale surface has undergone an elastic deformation and returned flat after contacting with $\mathrm{SiO}_{2}$ microsphere for the samples before acid treatment (Fig. 9c, e). Therefore, adhesion forces show a little change with different loading forces (Fig. 2d). After acid treatment, the dissolution of brittle minerals (calcite and dolomite) decreases the elastic modulus and the hardness, and leaves a rougher shale surface with a higher specific surface area. Because the spherical probe has a certain curvature, within relatively low loading forces, the number of molecules exposed to the adhesion zone would not increase significantly. However, when it comes to liquid molecules, rougher surface with increased specific surface area inevitably leads to more adsorption due to high dispersion degree of shale oil and gas. Figure $9 \mathrm{c}, \mathrm{d}$ gives a schematic demonstration why the adhesion forces are almost the same before and after acid treatment at low loading forces. It is worth noting that mineralogy composition would become more homogenized after acid digestion (Table 1). It may have played a vital role in bringing about concentrated adhesion force distribution (Fig. 10) at the loading force of $500 \mathrm{nN}$ for the post-acidizing group. As a consequence, the adsorption layer of shale oil/gas should be more evenly distributed after acid soaking.

When the loading force increases higher than the critical value, the contact surface becomes concave, and more molecules enter the adhesion zone contributing to the increased adhesion force (Fig. 9f). Therefore, at the mutual function of the increased specific surface area and ductile deformation, adhesion forces increased after acid treatment. The adhesion force also exhibits relatively severe fluctuations (Fig. 2b) due to the diversity of surface deformation and damage. Besides, with a rougher surface after acid treatment, higher energy dissipation from enhanced mechanical interlock and friction could also be a reason for the increased adhesion force.

Sorption and desorption of gas is one of the most important issues in shale gas development (Wang et al. 2018a, b; Xiong et al. 2017). A lot of simulation and macroscopic adsorption experiments have been conducted about this issue, and clay minerals, total organic carbon content, organic matter maturity, and kerogen type are considered as the main factors affecting gas storage capacity (Jodłowski et al. 2007; Wang et al. 2019, Wang and Sheng 2017; Zhang et al. 2012, 2018). However, there are few studies on shale adhesion characteristics that control the release of oil and gas at microscopic scales, especially in nanopores. Besides, carbonates have always been overlooked due to their low content. With the comparison of SEM images before and after acid treatment, we note that the effect of carbonates on surface topography is disproportionate to its content. Masses of cavities and pits form for the dissolution of non-uniformly distributed carbonates, which enlarged storage space and increased adsorption sites for shale oil/gas. By characterizing shale before and after acidification, we attribute these changes to the dissolution of carbonates. Our experiments show that shale exhibits a stronger adhesion capability in acidic environments, which means the desorption process becomes more difficult and is unfavorable for shale oil/gas development. Since the ultra-high vertical resolution of AFM (less than $1 \mathrm{~nm}$ ), the adhesion curve under the contact mode deserves particular concern, and it is believed to assist 

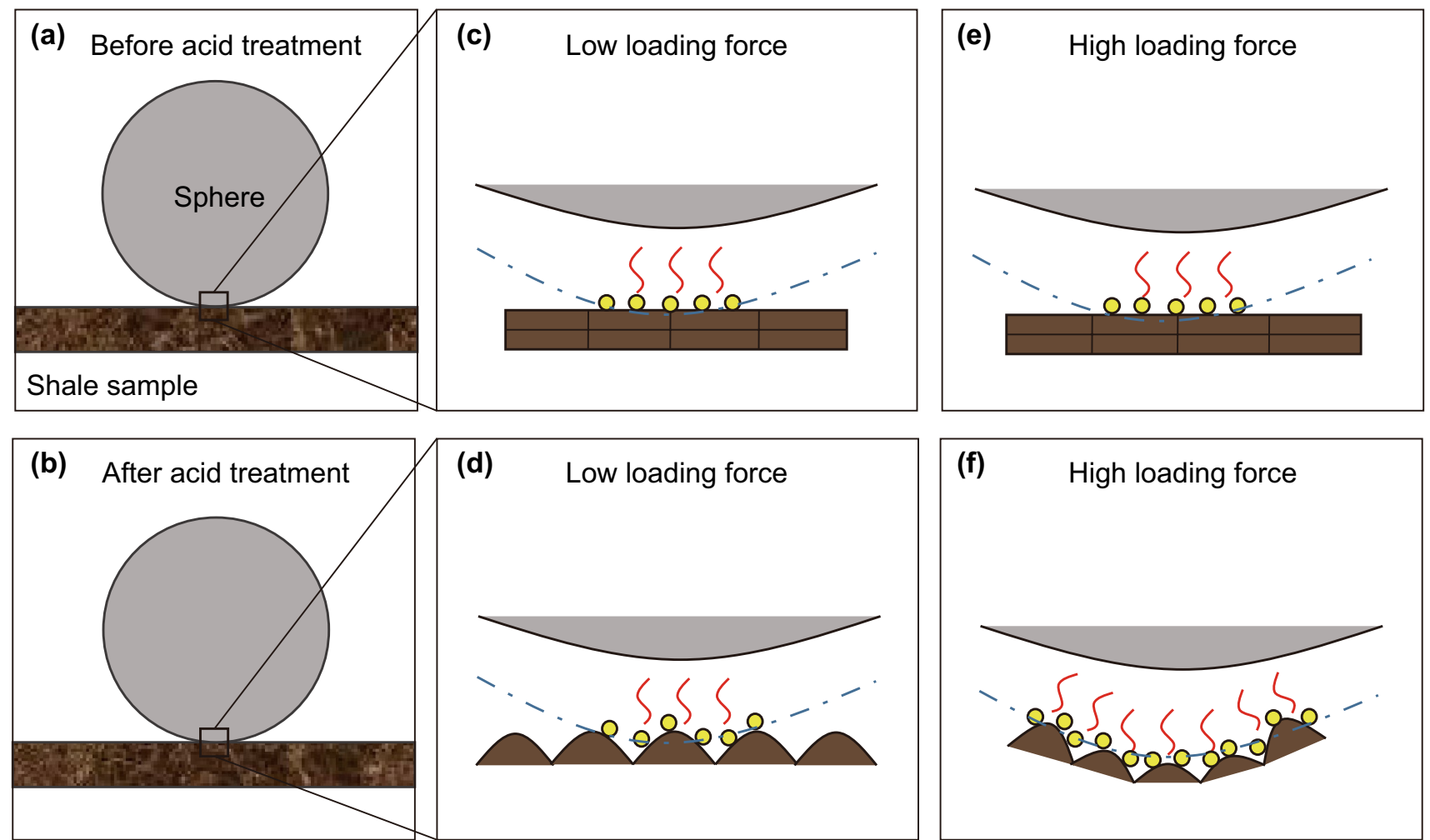

Fig. 9 Schematics of contact between $\mathrm{SiO}_{2}$ microsphere and shale surface $\mathbf{a}$ before and $\mathbf{b}$ after acid treatment. $\mathbf{c}, \mathbf{d}$ A zoom-in of box-region of $\mathbf{a}$ and $\mathbf{b}$ at low loading forces. $\mathbf{e}, \mathbf{f} \mathrm{A}$ zoom-in of box-region of $\mathbf{a}$ and $\mathbf{b}$ separately at high loading forces

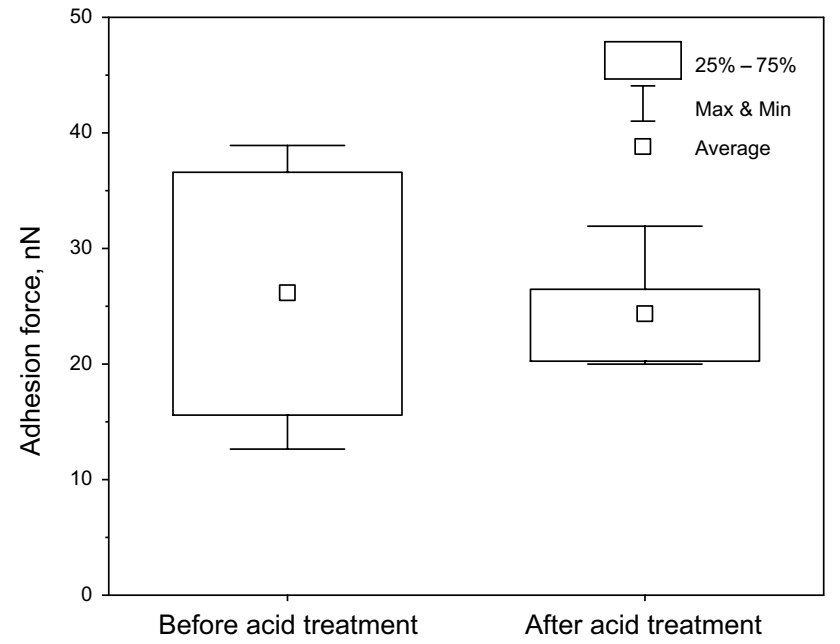

Fig. 10 Adhesion force distribution before and after acid treatment at the loading force of $500 \mathrm{nN}$

adsorption studies of shale gas and promote unconventional energy exploitation. We hope this preliminary research will stimulate more creative studies on this topic, especially for studies using nanoscale modified probes.

\section{Conclusions}

Multi-methods (AFM, FE-SEM, XRD, Nanoindentation) have been adopted to characterize the marine shale sample of Silurian Longmaxi Formation, Sichuan Basin, China. The effect of dilute acid treatment on adhesion properties of shale was innovatively revealed by AFM. Effects of dilute acid treatment on shale were obtained as follows:

(1) Combination of FE-SEM imaging and EDS scanning shows that a great many of cavities and pits can form due to the dissolution of carbonates after acid treatment. Contrary to the general belief that shale is relatively nonreactive to acidic fluids, morphology of shale changes significantly and microscale roughness increases due to the dissolution of heterogeneously distributed carbonates after acid treatment.

(2) Dilute acid treatment can greatly increase the adhesion force of shale. At different loading forces, adhesion forces remain stable before acid treatment. After acid treatment, adhesion forces show a platform-like rise and are more than trebled with the increase in loading force.

(3) Based on the experiment results, changes of the adhesion properties are attributed to alterations of topog- 
raphy and mechanical properties of shale. A dynamic model is proposed to explain enhanced adhesion forces of shale by dilute acid treatment. In this model, adhesion is achieved mainly through van der Waals forces. Increased specific surface area and reduced elastic modulus after acid treatment give a rational explanation for enhanced adhesion capability.

\begin{abstract}
Acknowledgements This work was financially supported by National Natural Science Foundation of China (No. 51674275), National Science and Technology Major Project (2017ZX05009-003), and PetroChina Innovation Foundation (2018D-5007-0308).

Open Access This article is distributed under the terms of the Creative Commons Attribution 4.0 International License (http://creativeco mmons.org/licenses/by/4.0/), which permits unrestricted use, distribution, and reproduction in any medium, provided you give appropriate credit to the original author(s) and the source, provide a link to the Creative Commons license, and indicate if changes were made.
\end{abstract}

\section{References}

Al-Harahsheh A, Al-Harahsheh M, Al-Otoom A, Allawzi M. Effect of demineralization of El-lajjun Jordanian oil shale on oil yield. Fuel Process Technol. 2009;90:818-24. https://doi.org/10.1016/j. fuproc.2009.03.005.

Binnig G, Quate CF, Gerber C. Atomic force microscope. Phys Rev Lett. 1986;56:930. https://doi.org/10.1103/physrevlett.56.930.

Butt H-J, Cappella B, Kappl M. Force measurements with the atomic force microscope: technique, interpretation and applications. Surf Sci Rep. 2005;59:1-152. https://doi.org/10.1016/j.surfr ep.2005.08.003.

Chen Y, Furmann A, Mastalerz M, Schimmelmann A. Quantitative analysis of shales by $\mathrm{KBr}$-FTIR and micro-FTIR. Fuel. 2014;116:538-49. https://doi.org/10.1016/j.fuel.2013.08.052.

Collell J, Galliero G, Vermorel R, Ungerer P, Yiannourakou M, Montel $\mathrm{F}$, et al. Transport of multicomponent hydrocarbon mixtures in shale organic matter by molecular simulations. J Phys Chem C. 2015;119:22587-95. https://doi.org/10.1021/acs.jpcc.5b07242.

Curtis JB. Fractured shale-gas systems. AAPG Bull. 2002;86:1921-38. https://doi.org/10.1306/61EEDDBE-173E-11D7-8645000102 C1865D.

Dai J, Zou C, Liao S, Dong D, Ni Y, Huang J, et al. Geochemistry of the extremely high thermal maturity Longmaxi shale gas, southern Sichuan Basin. Org Geochem. 2014;74:3-12. https://doi. org/10.1016/j.orggeochem.2014.01.018.

Ebnesajjad S, Landrock AH. Adhesives technology handbook. Norwich: William Andrew; 2014.

Grieser WV, Wheaton WE, Magness WD, Blauch ME, Loghry R. Surface reactive fluid's effect on shale. In: Production and operations symposium, 31 March-3 April, Oklahoma City, Oklahoma, U.S.A.; 2007. https://doi.org/10.2118/106815-MS.

Guo T, Li Y, Ding Y, Qu Z, Gai N, Rui Z. Evaluation of acid fracturing treatments in shale formation. Energy Fuels. 2017;31:10479-89. https://doi.org/10.1021/acs.energyfuels.7b01398.

Han Q, Qu Z, Ye Z. Research on the mechanical behaviour of shale based on multiscale analysis. R Soc Open Sci. 2018;5:181039. https://doi.org/10.1098/rsos.181039.
Huang F, Hu B. Macro/microbehavior of shale rock under the dynamic impingement of a high-pressure supercritical carbon dioxide jet. RSC Adv. 2018;8:38065-74. https://doi.org/10.1039/c8ra07480a.

Inui N, Iwasaki S. Interaction energy between graphene and a silicon substrate using pairwise summation of the lennard-jones potential. e-J Surf Sci Nanotechnol. 2017;15:40-9. https://doi.org/10.1380/ ejssnt.2017.40.

Ishida T, Aoyagi K, Niwa T, Chen Y, Murata S, Chen Q, et al. Acoustic emission monitoring of hydraulic fracturing laboratory experiment with supercritical and liquid $\mathrm{CO}_{2}$. Geophys Res Lett. 2012. https://doi.org/10.1029/2012g1052788.

Israelachvili JN. Intermolecular and surface forces. London: Academic press; 2011.

Javadpour F, Moravvej Farshi M, Amrein M. Atomic-force microscopy: a new tool for gas-shale characterization. J Can Pet Technol. 2012;51:236-43. https://doi.org/10.2118/161015-PA.

Jennings C. Surface roughness and bond strength of adhesives. J Adhes. 1972;4:25-38. https://doi.org/10.1080/00218467208072208.

Jia C, Zheng M, Zhang Y. Unconventional hydrocarbon resources in China and the prospect of exploration and development. Pet Explor Dev. 2012;39:139-46. https://doi.org/10.1016/s1876 -3804(12)60026-3.

Jiang Y, Luo Y, Lu Y, Qin C, Liu H. Effects of supercritical $\mathrm{CO}_{2}$ treatment time, pressure, and temperature on microstructure of shale. Energy. 2016;97:173-81. https://doi.org/10.1016/j.energ y.2015.12.124.

Jodłowski G, Baran P, Wójcik M, Nodzeński A, Milewska-Duda J. Sorption of methane and carbon dioxide mixtures in Polish hard coals considered in terms of adsorption-absorption model. Appl Surf Sci. 2007;253:5732-5. https://doi.org/10.1016/j.apsus c. 2006.12 .058 .

Kalra S, Tian W, Wu X. A numerical simulation study of $\mathrm{CO}_{2}$ injection for enhancing hydrocarbon recovery and sequestration in liquidrich shales. Pet Sci. 2018;15:103-15. https://doi.org/10.1007/ s12182-017-0199-5.

Kampman N, Bickle M, Wigley M, Dubacq B. Fluid flow and $\mathrm{CO}_{2}-$ fluid-mineral interactions during $\mathrm{CO}_{2}$-storage in sedimentary basins. Chem Geol. 2014;369:22-50. https://doi.org/10.1016/j. chemgeo.2013.11.012.

Kendall K. Adhesion: molecules and mechanics. Science. 1994;263:1720-5. https://doi.org/10.1126/science.263.5154.1720.

Lei M, Xu B, Pei Y, Lu H, Fu YQ. Micro-mechanics of nanostructured carbon/shape memory polymer hybrid thin film. Soft Matter. 2016;12:106-14. https://doi.org/10.1039/C5SM01269D.

Li Y-F, Sun W, Liu X-W, Zhang D-W, Wang Y-C, Liu Z-Y. Study of the relationship between fractures and highly productive shale gas zones, Longmaxi Formation, Jiaoshiba area in eastern Sichuan. Pet Sci. 2018;15:498-509. https://doi.org/10.1007/s1218 2-018-0249-7.

Liu K, Wang L, Ostadhassan M, Zou J, Bubach B, Rezaee R. Nanopore structure comparison between shale oil and shale gas: examples from the Bakken and Longmaxi Formations. Pet Sci. 2019;16:7793. https://doi.org/10.1007/s12182-018-0277-3.

Morsy S, Sheng J, Ezewu RO. Potential of waterflooding in shale formations. In: SPE Nigeria annual international conference and exhibition, 5-7 August, Lagos, Nigeria; 2013. https://doi. org/10.2118/167510-MS.

Paddy J, Johnson R, Kinloch A. Adhesion and adhesives: science and technology. London: Chapman and Hall; 1987.

Patton BJ, Pitts F, Goeres T, Hertfelder G. Matrix acidizing case studies for the Point Arguello Field. In: SPE Western regional/AAPG pacific section joint meeting, 19-24 May, Long Beach, California; 2003. https://doi.org/10.2118/83490-MS.

Qi W, Yun X, Xiaoquan W, Tengfei W, Zhang S. Volume fracturing technology of unconventional reservoirs: connotation, design 
optimization and implementation. Pet Explor Dev. 2012;39:37784. https://doi.org/10.1016/s1876-3804(12)60054-8.

Ribeiro $\mathrm{LH}, \mathrm{Li} \mathrm{H}$, Bryant JE. Use of a $\mathrm{CO}_{2}$-hybrid fracturing design to enhance production from unpropped-fracture networks. SPE Prod Oper. 2017;32:28-40. https://doi.org/10.2118/173380-PA.

Srodon J, Drits VA, McCarty DK, Hsieh JC, Eberl DD. Quantitative $\mathrm{X}$-ray diffraction analysis of clay-bearing rocks from random preparations. Clay Clay Miner. 2001;49:514-28. https://doi. org/10.1346/ccmn.2001.0490604.

Tang J, Wu K, Li Y, Hu X, Liu Q, Ehlig-Economides C. Numerical investigation of the interactions between hydraulic fracture and bedding planes with non-orthogonal approach angle. Eng Fract Mech. 2018;200:1-16. https://doi.org/10.1016/j.engfracmec h.2018.07.010

Tian S, Dong X, Wang T, Zhang R, Zhang P, Sheng M, et al. Surface properties of organic kerogen in continental and marine shale. Langmuir. 2018;34:13882-7. https://doi.org/10.1021/acs.langm uir.8b03151.

Tong J, Han X, Wang S, Jiang X. Evaluation of structural characteristics of huadian oil shale kerogen using direct techniques (Solid-state ${ }^{13} \mathrm{C}$ NMR, XPS, FT-IR, and XRD). Energy Fuel. 2011;25:4006-13. https://doi.org/10.1021/ef200738p.

Wan T, Liu H-X. Exploitation of fractured shale oil resources by cyclic $\mathrm{CO}_{2}$ injection. Pet Sci. 2018. https://doi.org/10.1007/s1218 2-018-0226-1.

Wang S, Feng Q, Javadpour F, Yang Y-B. Breakdown of fast mass transport of methane through calcite nanopores. J Phys Chem C. 2016;120:14260-9. https://doi.org/10.1021/acs.jpcc.6b05511.

Wang T, Tian S, Li G, Sheng M. Selective adsorption of supercritical carbon dioxide and methane binary mixture in shale kerogen nanopores. J Nat Gas Sci Eng. 2018a;50:181-8. https://doi. org/10.1016/j.jngse.2017.12.002.

Wang T, Tian S, Li G, Sheng M, Ren W, Liu Q, et al. Molecular simulation of $\mathrm{CO}_{2} / \mathrm{CH}_{4}$ competitive adsorption on shale kerogen for $\mathrm{CO}_{2}$ sequestration and enhanced gas recovery. J Phys Chem C. 2018b;122:17009-18. https://doi.org/10.1021/acs.jpcc.8b02061.

Wang T, Tian S, Li G, Sheng M, Ren W, Liu Q, et al. Experimental study of water vapor adsorption behaviors on shale. Fuel. 2019;248:168-77. https://doi.org/10.1016/j.fuel.2019.03.029.

Wang X, Sheng J. Gas sorption and non-Darcy flow in shale reservoirs. Pet Sci. 2017;14:746-54. https://doi.org/10.1007/s1218 2-017-0180-3.

$\mathrm{Wu} \mathrm{H}$, Chen J, Liu H. Molecular dynamics simulations about adsorption and displacement of methane in carbon nanochannels. J Phys Chem C. 2015;119:13652-7. https://doi.org/10.1021/acs. jpcc.5b02436.
Wu W, Sharma MM. Acid fracturing in shales: effect of dilute acid on properties and pore structure of shale. SPE Prod Oper. 2017;32:51-63. https://doi.org/10.2118/173390-MS.

Xiong J, Liu X-J, Liang L-X, Zeng Q. Investigation of methane adsorption on chlorite by grand canonical Monte Carlo simulations. Pet Sci. 2017;14:37-49. https://doi.org/10.1007/s12182-016-0142-1.

Xu Q, Li M, Niu J, Xia Z. Dynamic enhancement in adhesion forces of microparticles on substrates. Langmuir. 2013;29:13743-9. https ://doi.org/10.1021/la4023757.

Xu Q, Li M, Zhang L, Niu J, Xia Z. Dynamic adhesion forces between microparticles and substrates in water. Langmuir. 2014;30:111039. https://doi.org/10.1021/la502735w.

Yang F, Ning Z, Wang Q, Zhang R, Krooss BM. Pore structure characteristics of lower Silurian shales in the southern Sichuan Basin, China: insights to pore development and gas storage mechanism. Int J Coal Geol. 2016;156:12-24. https://doi.org/10.1016/j. coal.2015.12.015

Yang J, Bai R, Chen B, Suo Z. Hydrogel adhesion: a supramolecular synergy of chemistry, topology, and mechanics. Adv Funct Mater. 2019. https://doi.org/10.1002/adfm.201901693.

Yang N, Liu S, Yang X. Molecular simulation of preferential adsorption of $\mathrm{CO}_{2}$ over $\mathrm{CH}_{4}$ in Na-montmorillonite clay material. Appl Surf Sci. 2015;356:1262-71. https://doi.org/10.1016/j.apsus c.2015.08.101.

Yu Z, Liu L, Yang S, Li S, Yang Y. An experimental study of $\mathrm{CO}_{2}-$ brine-rock interaction at in situ pressure-temperature reservoir conditions. Chem Geol. 2012;326-327:88-101. https://doi. org/10.1016/j.chemgeo.2012.07.030.

Zhang B, Kang J, Kang T. Effect of water on methane adsorption on the kaolinite $\left(\begin{array}{lll}0 & 0 & 1\end{array}\right)$ surface based on molecular simulations. Appl Surf Sci. 2018;439:792-800. https://doi.org/10.1016/j.apsus c.2017.12.239.

Zhang S, Xian X, Zhou J, Zhang L. Mechanical behaviour of Longmaxi black shale saturated with different fluids: an experimental study. RSC Adv. 2017;7:42946-55. https://doi.org/10.1039/c7ra07179e.

Zhang T, Ellis GS, Ruppel SC, Milliken K, Yang R. Effect of organicmatter type and thermal maturity on methane adsorption in shale-gas systems. Org Geochem. 2012;47:120-31. https://doi. org/10.1016/j.orggeochem.2012.03.012.

Zhou Q, Xiao X, Tian H, Pan L. Modeling free gas content of the Lower Paleozoic shales in the Weiyuan area of the Sichuan Basin, China. Mar Pet Geol. 2014;56:87-96. https://doi.org/10.1016/j. marpetgeo.2014.04.001. 